\title{
Article \\ Low Velocity Impact Energy Monitoring and Recognition of Composite Laminates with Variable Thickness Based on Optical Fiber Sensor Network
}

\author{
Guan Lu ${ }^{1}$, Tianyu Zhu ${ }^{1}$ and Yiming $X u^{2, *}$ \\ 1 School of Mechanical Engineering, Nantong University, Nantong 226000, China; luguan@ntu.edu.cn (G.L.); \\ 18861351101@163.com (T.Z.) \\ 2 School of Electrical Engineering, Nantong University, Nantong 226000, China \\ * Correspondence: yimingx@ntu.edu.cn
}

check for

updates

Citation: Lu, G.; Zhu, T.; Xu, Y. Low Velocity Impact Energy Monitoring and Recognition of Composite

Laminates with Variable Thickness Based on Optical Fiber Sensor Network. Appl. Sci. 2021, 11, 584. https://doi.org/10.3390/app 11020584

Received: 10 December 2020

Accepted: 6 January 2021

Published: 8 January 2021

Publisher's Note: MDPI stays neutral with regard to jurisdictional clai$\mathrm{ms}$ in published maps and institutional affiliations.

Copyright: $(2021$ by the authors. Licensee MDPI, Basel, Switzerland. This article is an open access article distributed under the terms and conditions of the Creative Commons Attribution (CC BY) license (https:// creativecommons.org/licenses/by/ $4.0 /)$.

\begin{abstract}
At present, most of the research on low velocity impact of composite laminates focuses on load location and damage assessment. To provide further early warnings about structural impact damage, impact energy can be monitored and identified. For high strength composite laminates with variable thickness, in order to further accurately evaluate the impact energy, it is necessary to adopt more suitable dynamic load signal analysis and impact energy identification methods. Therefore, a new low velocity impact monitoring and identification method for composite plates with variable thickness is proposed. All impact sample signals collected by optical fiber sensor network are decomposed by whitening Empirical Mode Decomposition (EMD); the energy feature set is established according to the impact energy eigenvalue of sample signal; according to the first order component of signal decomposition, the thickness coefficient is determined and the energy feature set is modified to evaluate the actual impact energy. Meanwhile, combined with optical fiber sensing and signal processing technology, an impact energy monitoring system has been established, and the low velocity impact monitoring and identification experiments of composite laminates with variable thickness were carried out. The proposed energy identification method successfully identified 1-3 J impact energy with an average error of $4.82 \%$, and the average error of large thickness area with low sensitivity was significantly reduced from $13.25 \%$ to $5.67 \%$. The results show that the thickness coefficient correction method based on whitening EMD can evaluate the low velocity impact energy more accurately, and the thickness coefficient correction step significantly improves the recognition performance.
\end{abstract}

Keywords: structural monitoring; low velocity impact; impact energy recognition; variable thickness composite laminates; optic-fiber Bragg grating

\section{Introduction}

In recent years, composite materials used in aerospace, mechanical, marine, medical, construction, transportation, and other fields have increased significantly due to their superior mechanical properties over metal materials. Especially for weight-conscious structures, the advantage of lightweight makes composite materials one of the main structural materials. However, one of the major problems with composites is their sensitivity to impact damage. The types of damage that impact can cause include fiber breakage, matrix cracking, fiber/matrix degumming, and delamination of the laminate structure. This shows that impact damage is an important factor affecting the performance of composite materials [1].

Generally, impact can be divided into low velocity impact and high velocity impact, but there is no obvious boundary between them, and researchers have no unified understanding of their definitions. According to Sjŏblom et al., low velocity impact is a quasi-static impact event, the upper limit of which can reach tens of meters per second, 
depending on the stiffness of the target, material properties and the mass and stiffness of the impact object [2]. Liu et al. proposed that the types of impact can be classified according to the damage caused by impact. The main characteristics of high velocity impact are fiber fracture, while the main characteristics of low velocity impact are matrix cracking and delamination [3]. Aviation low velocity impact mainly refers to the impact of $5 \mathrm{~J}$ and below, mainly refers to the impact of tools falling or small particles splashing in the process of aircraft manufacturing and service.

Composite laminates may revert to their original shapes after being subjected to an impact. Due to their brittleness, the composite laminate may suffer substantial internal damage without any visible damage, especially internal cracks or delamination caused by external low velocity impact. These forms of damage, most of which are hidden in the composite structure, can result in significant degradation of the mechanical properties of the composite structure [4]. Further development of these forms of damage can seriously endanger the operation of the structure and can lead to catastrophic failure of the entire structure. Therefore, the impact damage of the composite laminate structure must be monitored as early as possible.

The damage mechanism of composite materials is more complicated than that of traditional isotropic materials. In addition, it is very difficult to detect the Barely Visible Impact Damage (BVID) to the composites [5]. At present, it is through regular inspection and maintenance to ensure the safety and efficiency of the structure. However, BVID may be generated before regular maintenance due to unforeseen events; in addition, impact damage caused by external impact or internal object dropouts may be overlooked during the inspection. These events can cause structural problems that can lead to serious accidents. Therefore, health monitoring of composite structures is required to detect and locate all low velocity impacts that could result in BVID [6]. Determining impact location and impact energy helps to assess structural health, especially for evaluating BVID.

The strength of composite board with variable thickness is usually higher than that of common composite board, but the signal analysis under dynamic load is more complicated. However, the real-time monitoring of composite board with variable thickness of impact signal can early warning the structural low velocity impact damage [7]. In recent years, scholars from all over the world have made some research on the structure of variable thickness of composite materials. Bacciocchi et al. performed the free vibration analysis of several laminated composite doubly curved shells, singly curved shells and plates, characterized by a continuous thickness variation [8]; Tornabene et al. presented the fundamental nuclei for doubly curved structures in their explicit form for the first time, which also allow considering doubly curved structures with variable thickness [9]. At present, the research on the structure of variable thickness composite laminates mainly focuses on mechanical analysis and finite element simulation $[10,11]$. Because of the severe aliasing of the impact signal of the composite with variable thickness, there are few public reports on impact monitoring. At present, there are many sensors that can be used to monitor the impact load of composite laminates. Fiber Bragg Grating (FBG) sensors have been widely used due to their advantages of light weight, small volume, corrosion resistance, interference resistance, distribution, and good insulation [12,13]. Park et al. used impact signals obtained from four FBG sensors on a composite stiffened plate using two methods of wavelet decomposition and neural network for the impact location of two impact energy levels [14]. The feasibility of this method was verified by experiments. Hiche et al. studied a positioning algorithm based on strain amplitude, which locates the impact source by comparing the absolute value of the maximum strain amplitude of the impact signals measured by the FBG sensor array [15]. The algorithm can identify the position of low velocity impact and only requires the relative position information between sensors. This method requires minimal structural information and sensors, and is validated only on epoxy composite panels. Park et al. proposed a method which uses dynamic strain signals acquired by FBG sensors for impact location recognition [16]. The estimated location and strain signals were trained by neural networks to reconstruct multi-characteristic impact forces, but only 
for simple impact problems. Jang et al. proposed an impact localization algorithm based on dynamic strain history caused by external low velocity impact [17]. They compared the RMS values between the reference signal database and the new acquisition impact signal, and used the acoustic emission signals obtained by the FBG to perform the impact localization. The proposed algorithm was applied to the composite stiffener. However, little current research is concerned with the impact energy monitoring of variable thickness composite structures. According to author's previous studies on impact location, it is found that the impact load location can only provide the basis for the impact damage location. In order to evaluate the impact damage situation more accurately, it is necessary to identify the impact energy.

To monitor and identify the low velocity impact energy of composite laminates with variable thickness on aviation specimens, the fiber Bragg grating sensing technology $[18,19]$ with the advantages of anti-interference and distribution is applied to the low velocity impact monitoring, and the impact energy identification system is established. In addition, a new low velocity impact monitoring and identification method for variable thickness composite plate is proposed. The key algorithm of whitening Empirical Mode Decomposition (EMD) is used to extract the eigenvalues of the impact signal of variable thickness plate with serious aliasing, and then the low velocity impact energy level is identified, which ensures the effectiveness of impact location early warning.

\section{Impact Energy Recognition Algorithm Based on Fiber Bragg Grating Strain Sensing Technology}

\subsection{Fiber Bragg Grating Strain Sensing Technology}

Fiber Bragg gratings produce a narrow-band reflection of incident light that meets the grating reflection condition. The ideal grating wavelength is:

$$
\lambda=2 n_{e f f} \Lambda
$$

$\Lambda$ is the grating pitch, $n_{e f f}$ is the effective refractive index [20]. Due to the flare effect and the expansion and contraction of the grating pitch, the grating undergoes a change in wavelength when it is exposed to stress. Assuming that the fiber Bragg grating sensor at this time is only subjected to the tensile strain $\epsilon$, from the grating period and the basic principles of the formula can be drawn:

$$
\frac{\Delta \lambda}{\lambda}=(1-P) \cdot \varepsilon
$$

$P$ is a valid flare function. From Formula (2) it can be seen that the wavelength of the fiber Bragg grating shifts linearly with the longitudinal strain at constant temperature. The effect of external low velocity impact load on the structure can cause the center wavelength of fiber Bragg grating sensor shift, hence FBG sensor can be used in the research of low velocity impact monitoring of variable thickness composite laminates.

\subsection{Low Velocity Impact Feature Extraction Algorithm}

Signal amplitude, spectral amplitude, wavelet transform, the EMD algorithm, and other methods can be used for feature extraction of the low velocity impact signal detected by grating sensor. Due to the characteristics of the composite material with variable thickness, each order component of the classical EMD algorithm is approximately orthogonal, but the frequency aliasing is serious [21]. Therefore, an improved whitening EMD algorithm is proposed here to directly decompose several independent Intrinsic Mode Function(IMF) components from high frequency to low frequency from complex time series, and then spectrum analysis is carried out to obtain the impact eigenvalue. The main function of the standard EMD algorithm is to remove the signal superimposed wave and make the data waveform more symmetrical [22]. Whitening the EMD algorithm can whiten the component matrix to reduce the aliasing and eliminate the need for multiple sampling, 
avoiding the serious problem of modal aliasing of the original modal signal, and increase the accuracy of energy recognition.

In the first step, using the EMD algorithm, any original signal $M(t)$ can be decomposed into Formula (3). $S_{i}^{\prime}(t)$ is the decomposition volume, $r_{n}(t)$ is the signal residual. The firstorder component $S_{1}^{\prime}(t)$ contains the highest frequency component of $M(t)$, and $r_{n}$ indicates the trend of the signal. Using the standard deviation of the continuous treatment results as the basis of the judgment of whether the decomposition process can be terminated or not, the standard deviation is taken as 0.3 , one of the following conditions is satisfied, and the screening process can be terminated: $S_{n}^{\prime}(t)$ or $r_{n}(t)$ is less than the predetermined error; $r_{n}(t)$ is a monotonous function.

$$
\sum_{i=1}^{n} S_{i}^{\prime}(t)+r_{n}(t)
$$

In the second step, correlation matrix values of whitening are obtained in Formula (4). $x$ is a random signal, $\mathrm{R}$ is the cumulative matrix, $\Sigma^{-1} R^{T}$ is the whitening matrix. Whitening EMD algorithm also need to meet the following conditions: The similarity between each component is less than the predetermined threshold; The $\mathrm{Z}$ matrix of $S_{i}^{\prime}(t)$ is whitened to reduce aliasing. From this, each order component $S_{i}(t)$ is obtained.

$$
W_{x}=R \Sigma^{2} R^{T}
$$

In the third step, we discuss the orthogonality of the component $S_{i}(t)$, which is obtained from the decomposition formula and the whitening correlation matrix is obtained from Formula (5). Where $S_{n+1}(t)=r_{n}(t)$. If the component $S_{i}(t)$ is orthogonal, then the second term to the right of Formula (5) should be 0, global orthogonal exponent is obtained in Formula (6). Then the orthogonal exponent of any two components $S_{k}, S_{j}$ can be obtained from Formula (7). The components of each order are orthogonal, and because each component is decomposed from the original data, the whitening EMD algorithm has better self-adaptability.

$$
\begin{gathered}
M^{2}(t)=\sum^{n+1} s_{i}^{2}(t)+2 \sum^{n+1} \sum^{n+1} s_{i}(t) s_{k}(t) \\
\sum_{i=0}^{T}\left(\sum_{j=1}^{n+1} \sum_{k=1}^{n+1} s_{j}(t) s_{k}(t) / M^{2}(t)\right) \\
\sum_{i=0}^{T} \frac{s_{k} s_{j}}{s_{k}+s_{j}}
\end{gathered}
$$

The above derivation process shows that the proposed whitening EMD algorithm avoids the serious problem of modal aliasing of the original modal signal, effectively improves the signal processing rate, improves the validity of the impact feature and increases the accuracy of energy recognition. Unlike standard algorithms, this improved algorithm eliminates the need for multiple samplings and has practical effects on engineering specimens that are susceptible to impact.

\subsection{Low Velocity Impact Energy Recognition Steps}

In the low velocity impact energy monitoring and recognition process, the low velocity impact energy is evaluated by the impact energy feature of the sample signals. First of all, all the sample impact signals and the signal to be measured need to be whitening EMD decomposed. Secondly, calculate the eigenvalues of the impact energy of the sample signals and the signal to be measured, i.e., the spectral peak of a certain order component of the signals in the sensor network, and establish the energy feature set of the sample impact signals. Finally, because the smaller thickness area of the specimen plate is more sensitive to the impact energy, the integrated thickness coefficient is determined according to a certain 
order component of the sensor network signals, which is used to correct the energy feature set and achieve the actual impact energy assessment. In summary, the specific steps of low velocity impact energy recognition algorithm for variable thickness composite laminates are as follows:

(1) At the key impact position, the low velocity impact sample signals with multiple impact energies are collected and decomposed by whitening EMD, and then the crosscorrelation coefficients between each component and the original signal are obtained.

(2) The components with large correlation coefficients are selected for spectrum analysis to get the spectrum peak set; the first or second order components (judged according to the actual aliasing of decomposition) are used for spectrum analysis to get the peak number set, and the comprehensive thickness coefficient set is obtained after normalization.

(3) The spectrum peak set of the variable thickness plate is obtained by modifying the spectrum peak set with the comprehensive thickness coefficient set, and the maximum value of the set is obtained as the energy eigenvalue of the impact sample signal. Based on this, feature sets of variable thickness plates with multiple energies are established.

(4) The collected energy impact signal $Z$ whose energy is to be measured is decomposed by whitening EMD, and the eigenvalue $f$ and range values of variable thickness plate feature set $F$ are compared to evaluate the impact energy level. If the eigenvalue $f$ is between the feature sets $F_{1}$ and $F_{2}$ of two levels of energy $E_{1}$ and $E_{2}$, the evaluation is based on $f$ and the energy feature set boundaries $F_{1 \max }$ and $F_{2 \min }$ :

$$
E_{z}=E_{2}-\frac{\left(F_{2 \min }-f\right) \cdot\left(E_{2}-E_{1}\right)}{F_{2 \min }-F_{1 \max }}
$$

Shown in Figure 1 is the low velocity impact energy recognition flow chart of variable thickness composite laminates. The thickness correction step is to compensate for the distortion of the variable thickness structure signal, and to improve the recognition effect of impact energy by using the thickness feature in the spectrum.

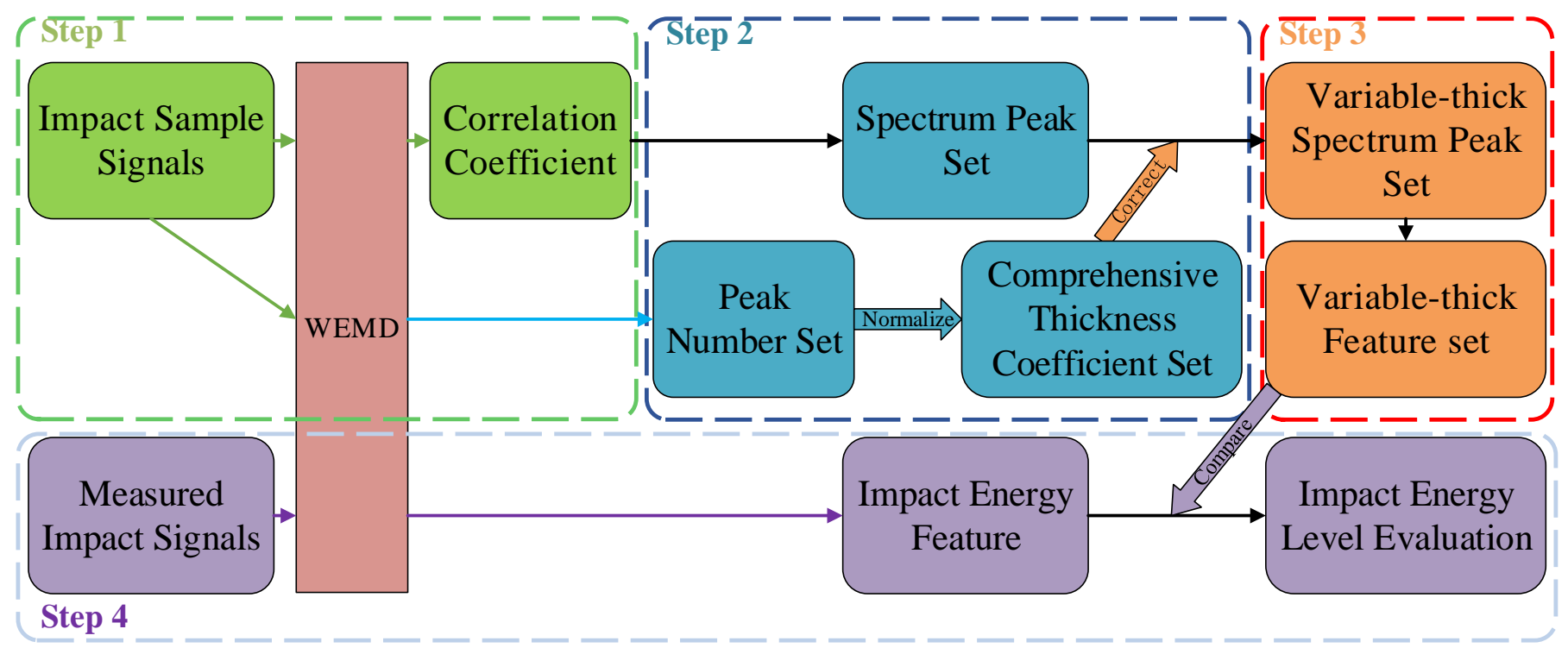

Figure 1. Low velocity impact energy recognition flow chart of variable thickness composite laminates. 


\section{Low Velocity Impact Experiment}

\subsection{Low Velocity Impact Experimental System for Variable Thickness Composite Laminates}

As shown in Figure 2, the low velocity impact experimental system consists of variable thickness composite laminates on the wing tank specimen, fiber Bragg grating sensors, impact hammer, SI425 fiber grating demodulator and computer. The material of the variable thickness composite specimen surface is carbon fiber T300/QY8911 (the material parameters are shown in Table 1, the layer structure is shown in Table 2), the fiber type is TG, manufactured using a unidirectional tape. The thickness range of the layer is $45 \mathrm{~mm}-47.5 \mathrm{~mm}$ (different thickness areas are distinguished by different colors, and the thickness value is marked in the upper left corner of the area with the corresponding color), the size is $600 \mathrm{~mm} \times 300 \mathrm{~mm}$, the width of the metal solid bracket border is $40 \mathrm{~mm}$. Since the laminates with different properties can be obtained by laying the single-layer panels in different main directions, the skin ply structure in Table 2 is designed according to the specific strength requirements of the wing oil tank. As shown in Figure 3, the region shown by the slash is an impact experimental area with $240 \mathrm{~mm} \times 200 \mathrm{~mm}$ size, and divided into the grid of $40 \mathrm{~mm} \times 40 \mathrm{~mm}$ size, as shown in Figure 4. The length of the 6 FBG sensors pasted on the surface is $10 \mathrm{~mm}$, the sensor arrangement shown in Figure 4, the sensor wavelength and position shown in Table 3. The energy of the hand-held impact hammer is third gear adjustable (1 J, $2 \mathrm{~J}, 3 \mathrm{~J})$, and it can impact on the surface anywhere. The impact hammer head is spherical, because the contact surface and energy are small enough, it is analyzed as a plane. The 1-3 J energy belongs to the lower range of aviation low velocity impact, so the impact process can be regarded as completely elastic impact. The SI425 optical fiber grating demodulator has four optical channels, and it can connect up to 512 fiber Bragg grating sensors through the FC/PC interface for static and dynamic signal measurement; with detection wavelength range of $1520 \mathrm{~nm}-1570 \mathrm{~nm}$, resolution $1 \mathrm{pm}$, dynamic range of $25 \mathrm{~dB}$, scanning frequency of $250 \mathrm{~Hz}$. The impact experiment system acquires the impact response signals by monitoring the wavelength shift value of the fiber Bragg grating sensor. When the impact hammer impacts on the specimen, the demodulator transmits the impact signals collected by the 6 sensors to the computer. Based on the vibration test of composite laminates with variable thickness, ply thickness gradients, symmetries, fixations and mechanical analysis, at the same time, in order to detect the strain field changes of the whole variable thickness area, sensors were arranged at six locations of the boundary of the test area. The six sensors were calibrated by four points bending test before they were pasted on the specimen, and the grating strain sensitivity is about $1.198 \mathrm{pm} / \mu \varepsilon$ at room temperature of $20^{\circ} \mathrm{C}$. Combined with the demodulator resolution of $1 \mathrm{pm}$, it shows that all grating sensors can monitor the structural strain changes. 


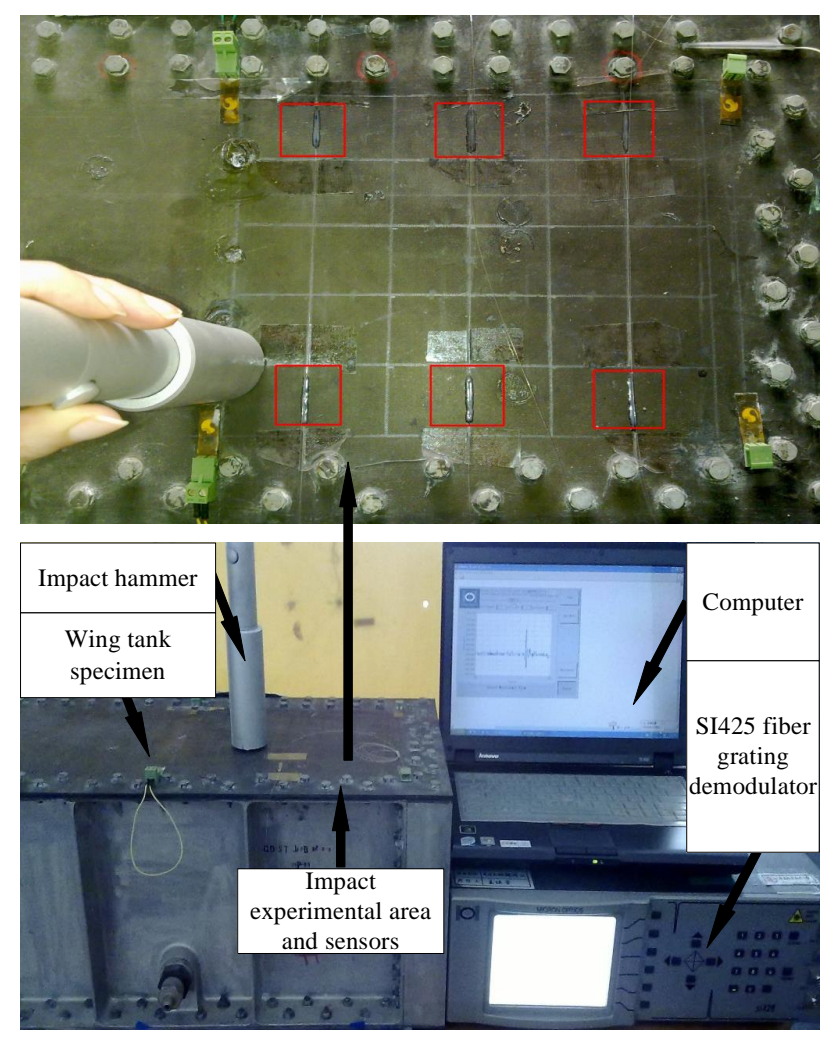

Figure 2. Wing tank low velocity impact monitoring system based on fiber Bragg grating sensor.

Table 1. Composite T300/QY8911 material parameters [23].

\begin{tabular}{llllll}
\hline$E_{\mathbf{1 1}}(\mathrm{GPa})$ & $E_{\mathbf{2 2}}(\mathrm{GPa})$ & $G_{\mathbf{1 2}}(\mathrm{GPa})$ & $G_{\mathbf{2 3}}(\mathrm{GPa})$ & $\rho\left(\mathrm{g} / \mathrm{cm}^{3}\right)$ & $\mu$ \\
\hline 135 & 8.8 & 4.47 & 3.45 & 1.56 & 0.3 \\
\hline$E_{i j}$-Elastic Modulus; $G_{i j}$-Shear modulus; $\rho$-density; $\mu$-Poisson's ratio.
\end{tabular}

Table 2. The layer structure of the composite laminated plate.

\begin{tabular}{|c|c|c|c|c|c|c|c|}
\hline $\begin{array}{l}\text { Layer } \\
\text { Number }\end{array}$ & $\begin{array}{l}\text { Angle } \\
\text { (Degree) }\end{array}$ & $\begin{array}{l}\text { Layer } \\
\text { Number }\end{array}$ & $\begin{array}{l}\text { Angle } \\
\text { (Degree) }\end{array}$ & $\begin{array}{l}\text { Layer } \\
\text { Number }\end{array}$ & $\begin{array}{l}\text { Angle } \\
\text { (Degree) }\end{array}$ & $\begin{array}{l}\text { Layer } \\
\text { Number }\end{array}$ & $\begin{array}{l}\text { Angle } \\
\text { (Degree) }\end{array}$ \\
\hline 1 & 45 & 15 & 45 & 29 & -45 & 43 & 0 \\
\hline 2 & 0 & 16 & 0 & 30 & 0 & 44 & -45 \\
\hline 3 & -45 & 17 & -45 & 31 & 45 & 45 & 0 \\
\hline 4 & 90 & 18 & 0 & 32 & 0 & 46 & 0 \\
\hline 5 & 0 & 19 & 0 & 33 & -45 & 47 & 45 \\
\hline 6 & 45 & 20 & 45 & 34 & 0 & 48 & 0 \\
\hline 7 & 0 & 21 & 0 & 35 & 90 & 49 & 45 \\
\hline 8 & 45 & 22 & 90 & 36 & 0 & 50 & 0 \\
\hline 9 & 0 & 23 & 0 & 37 & 45 & 51 & 45 \\
\hline 10 & 45 & 24 & -45 & 38 & 0 & 52 & 0 \\
\hline 11 & 0 & 25 & 0 & 39 & 0 & 53 & 90 \\
\hline 12 & 0 & 26 & 45 & 40 & -45 & 54 & -45 \\
\hline 13 & -45 & 27 & 0 & 41 & 0 & 55 & 0 \\
\hline 14 & 0 & 28 & -45 & 42 & 45 & 56 & 45 \\
\hline
\end{tabular}




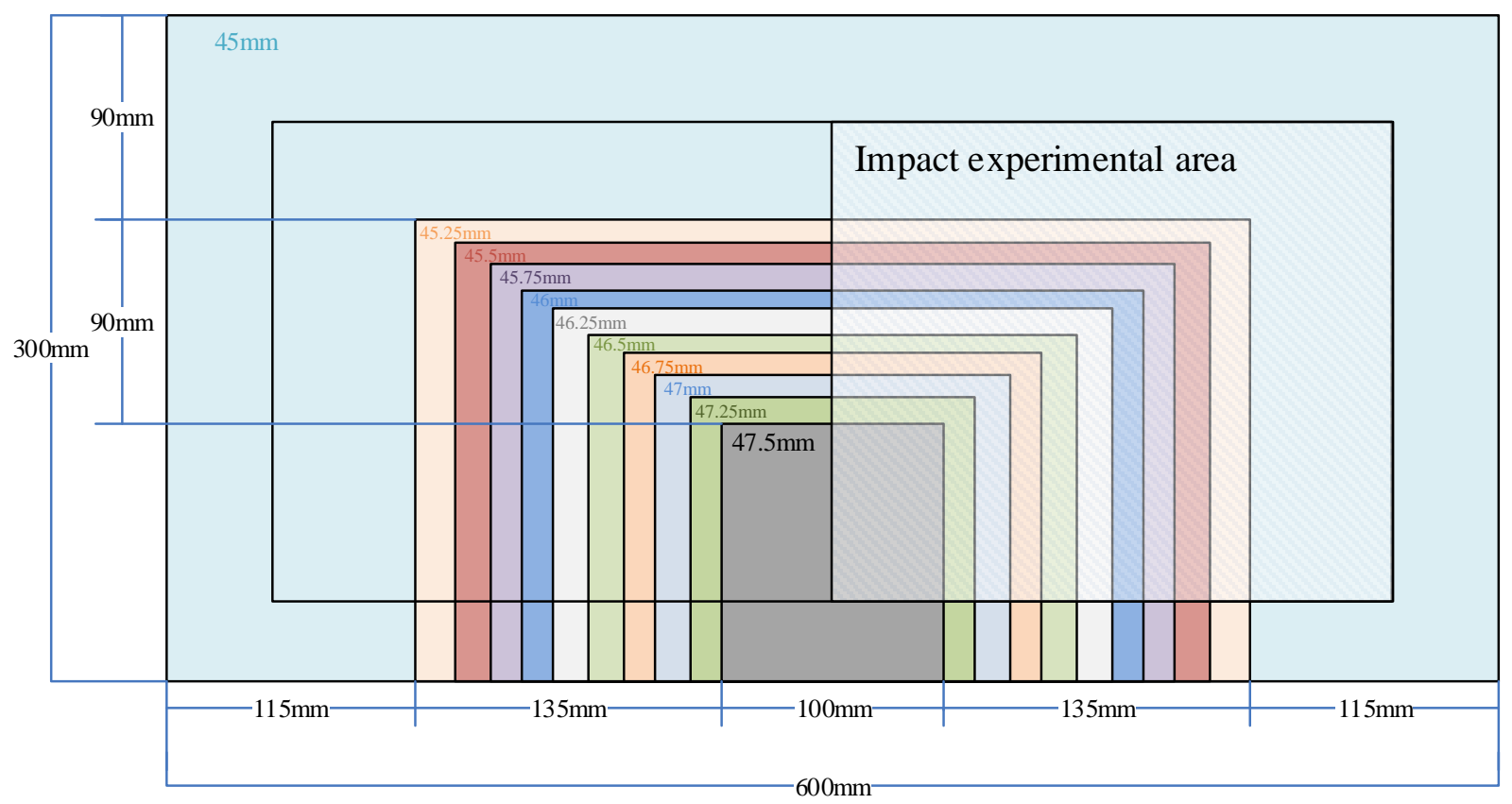

Figure 3. Layer thickness variation of composite laminate on specimen surface.

Table 3. Grating wavelength and position.

\begin{tabular}{lll}
\hline Sensor & Center Wavelength $(\mathbf{n m})$ & Location $(\mathbf{m m})$ \\
\hline FBG1 & 1529.939 & $(40,20)$ \\
FBG2 & 1527.045 & $(120,20)$ \\
FBG3 & 1535.118 & $(200,20)$ \\
FBG4 & 1530.090 & $(40,180)$ \\
FBG5 & 1555.793 & $(120,180)$ \\
FBG6 & 1535.064 & $(200,180)$ \\
\hline
\end{tabular}

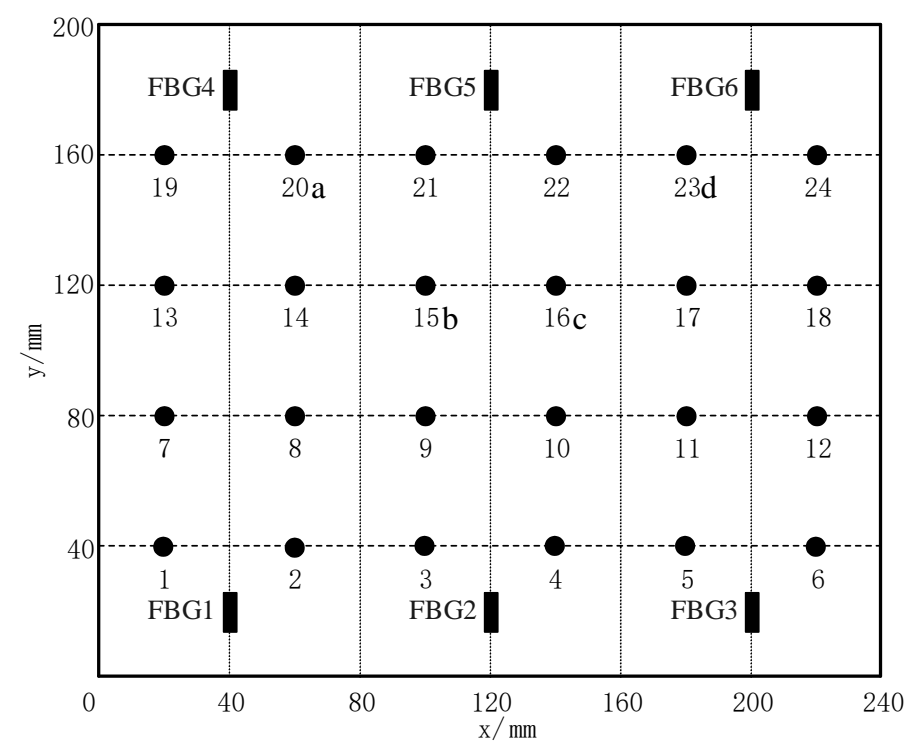

Figure 4. Impact point and sensor position diagram. 


\subsection{Build a Sample Low Velocity Impact Signal Database}

To establish a sample signal database of the variable thickness composite laminate for impact energy recognition, impact points of 24 grid lines in the impact experimental area were impacted respectively using impact hammers with $1 \mathrm{~J}, 2 \mathrm{~J}$, and $3 \mathrm{~J}$ impact energy, as shown in Figure 4. Each sample signal is sampled at a sampling rate of $250 \mathrm{~Hz}$ for $0.8 \mathrm{~s}$, i.e., the number of sampling times is 200 and the resulting frequency range is 0 to $125 \mathrm{~Hz}$. Figure 5 shows an example of sample low velocity impact signals collected by 6 FBG sensors, and take the impact points $(60 \mathrm{~mm}, 160 \mathrm{~mm})$ with the $1 \mathrm{~J}, 2 \mathrm{~J}$ and $3 \mathrm{~J}$ energy as an example. The change of the waveform and the amplitude characteristic of the sample signal is related to the change of impact energy, but the impact energy cannot be identified by directly comparing the time-domain characteristics of the impact signal.

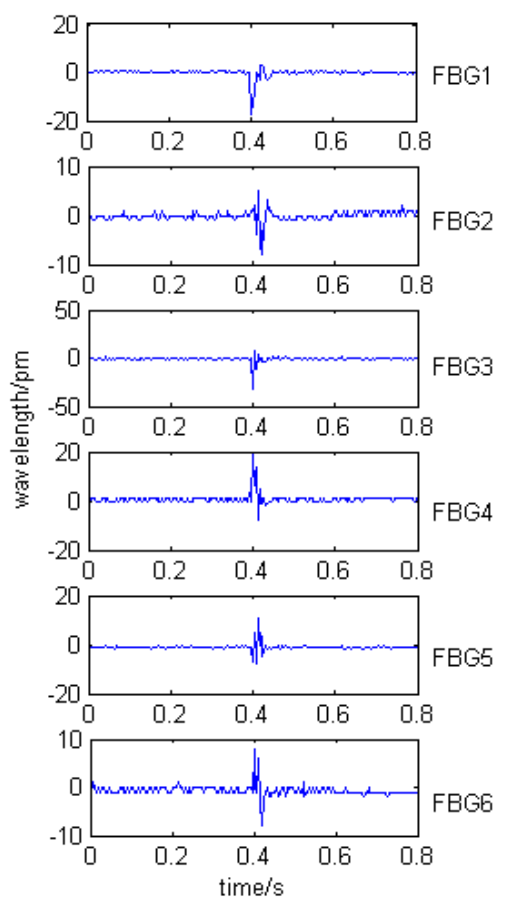

(a) Signals at $(60 \mathrm{~mm}, 160 \mathrm{~mm})$ with $1 \mathrm{~J}$.

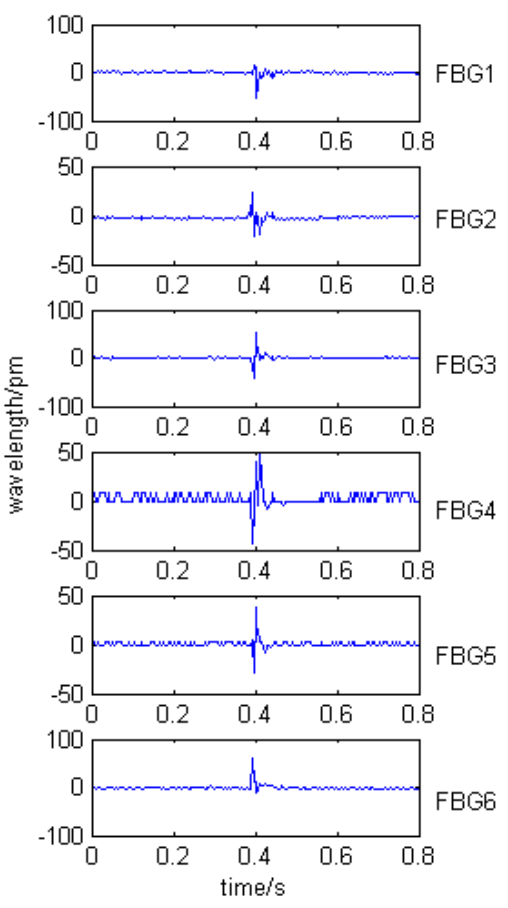

(b) Signals at $(60 \mathrm{~mm}, 160 \mathrm{~mm})$ with $2 \mathrm{~J}$.

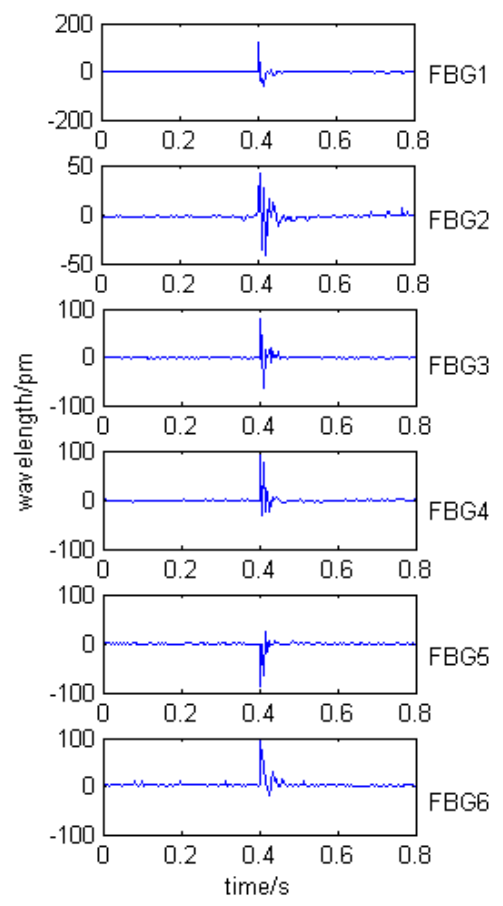

(c) Signals at $(60 \mathrm{~mm}, 160 \mathrm{~mm})$ with $3 \mathrm{~J}$.

Figure 5. Sensing network signals at impact point $(60 \mathrm{~mm}, 160 \mathrm{~mm})$ with $1 \mathrm{~J}, 2 \mathrm{~J}, 3 \mathrm{~J}$.

The situation is more complicated while identifying the impact signal energy at different impact positions. As shown in Figure 6 are the sample impact signals collected by a single sensor at different impact positions with the same impact energy, take the signals at point a, b, c, d with $2 \mathrm{~J}$ impact energy as an example. As shown in Figure 6a, the change of impact location and thickness makes it very difficult to directly obtain the impact energy eigenvalue from the time-domain signal; as shown in Figure 6b, the frequency aliasing in the Fourier transform spectrum of the time-domain signal is severe. Therefore, the impact energy needs to be analyzed and identified by the impact energy feature extraction algorithm. 

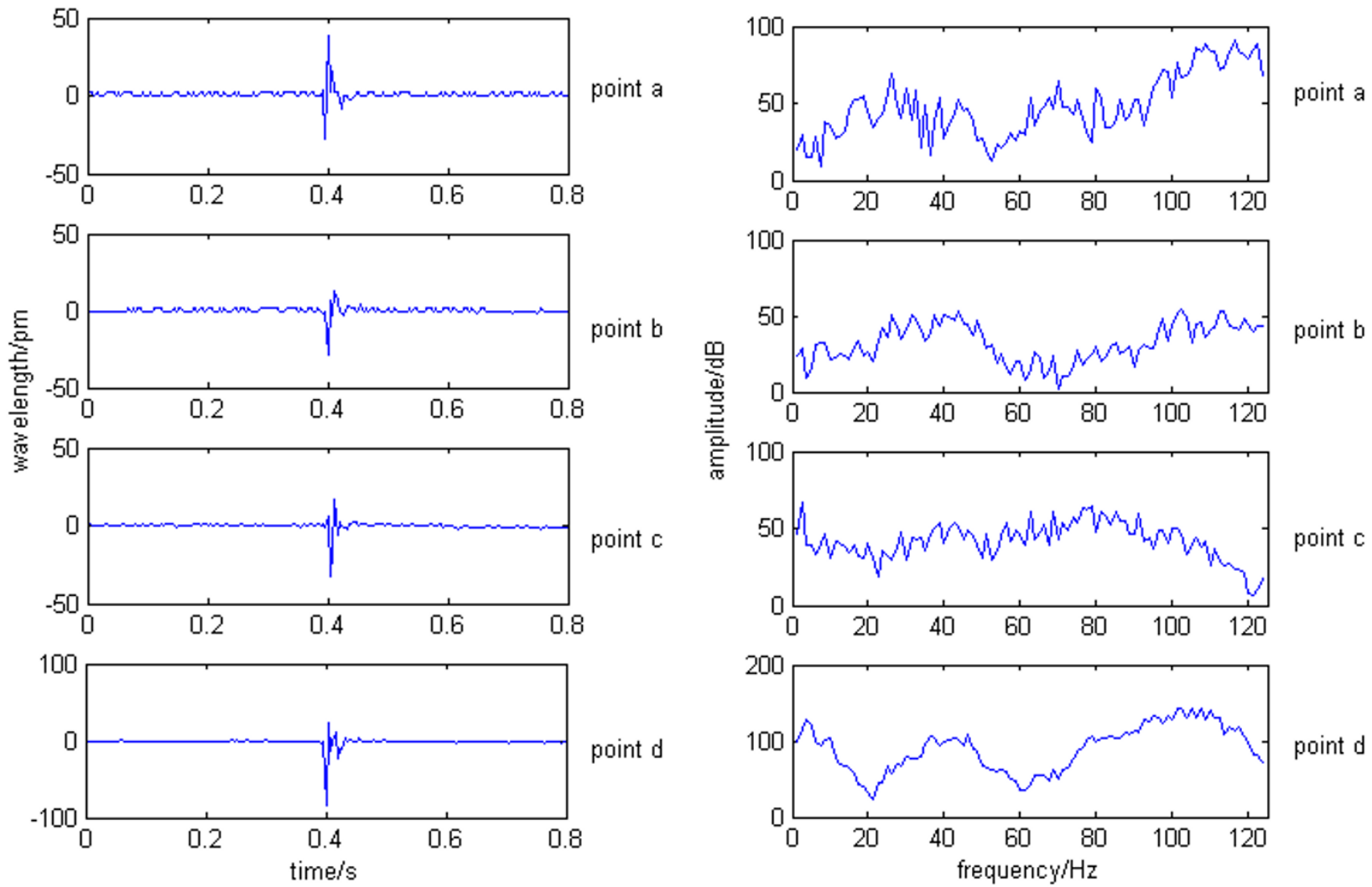

(a) impact signals.

(b) frequency spectrum.

Figure 6. Impact response signals and spectrogram of sensor No. 5 with $2 \mathrm{~J}$.

\section{Analysis of Low Velocity Impact Experimental Results}

4.1. Establishment of a Low Velocity Impact Energy Feature Set for Variable Thickness Laminates

Because the classical spectrum analysis can provide less effective signal feature information and more aliasing, the improved whitening EMD can be used to analyze the impact signals of variable thickness composite laminates. Taking the impact signals at position a, b, c, and d in Figure 6 as an example.

Figure 7 shows the decomposition result of the whitening EMD algorithm, from the above to bottom are the IMF components obtained after decomposition and one residual component. Cross-correlation calculation of each order IMF component with the impact response signals shown in Figure $6 \mathrm{a}$ is carried out respectively, and get the following conclusion in Table 4: The correlation coefficient $q$ of the first three components of whitening EMD algorithm is relatively larger, and the coefficients are all less than 0.1 from the first four components onward; all the components of the whitening EMD algorithm better cover the frequency range of the band where the original signal is located and are more independent. 


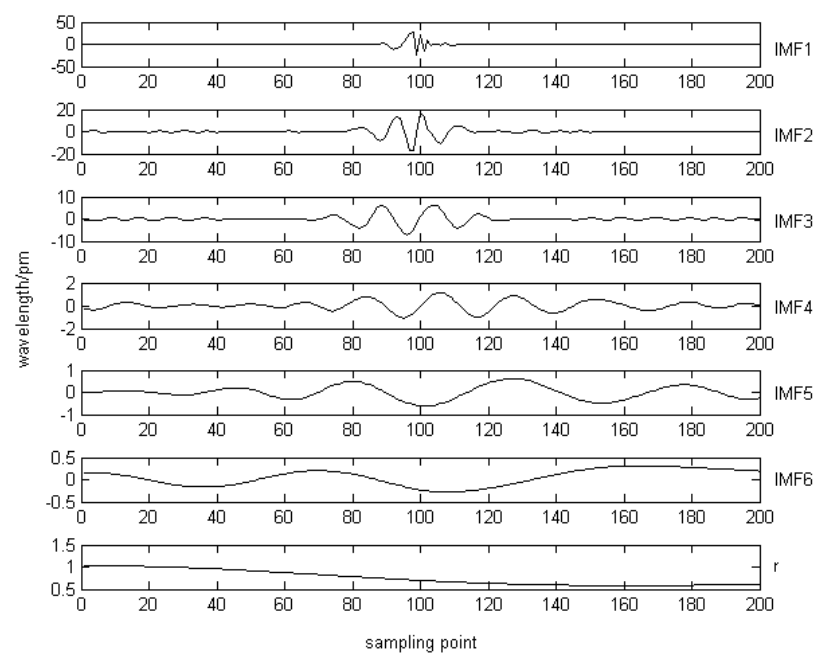

(a) The component graph of the impact signals at point a.
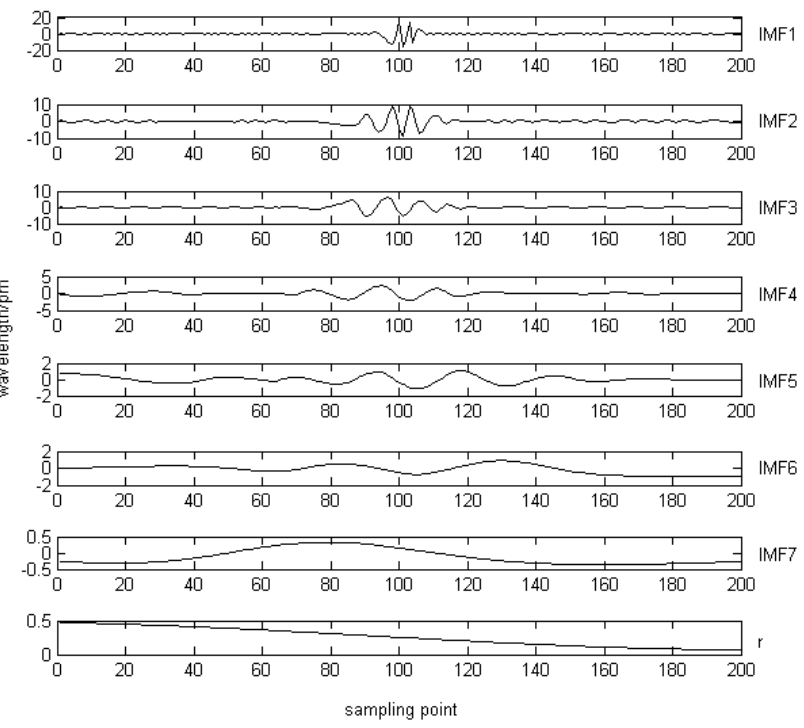

(c) The component graph of the impact signals at point c.

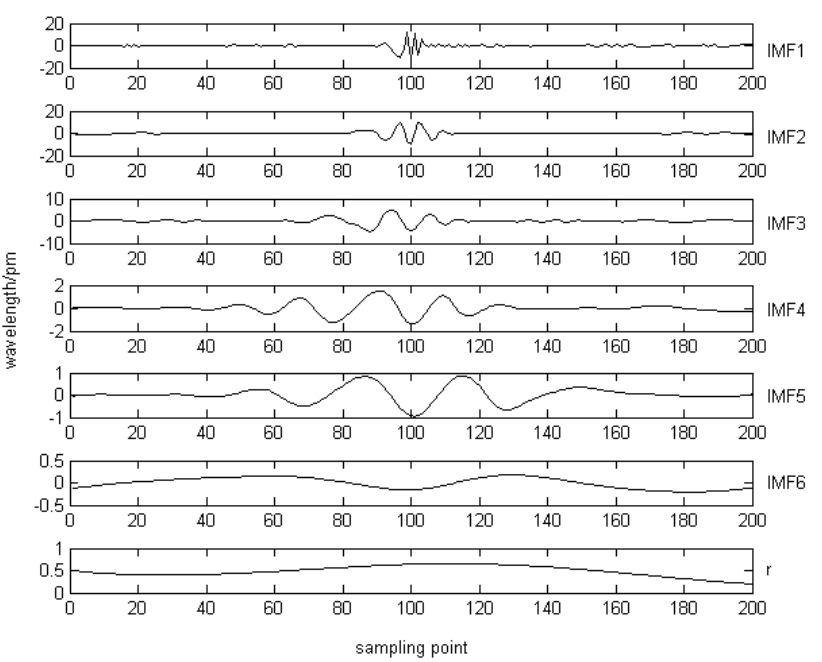

(b) The component graph of the impact signals at point $b$.

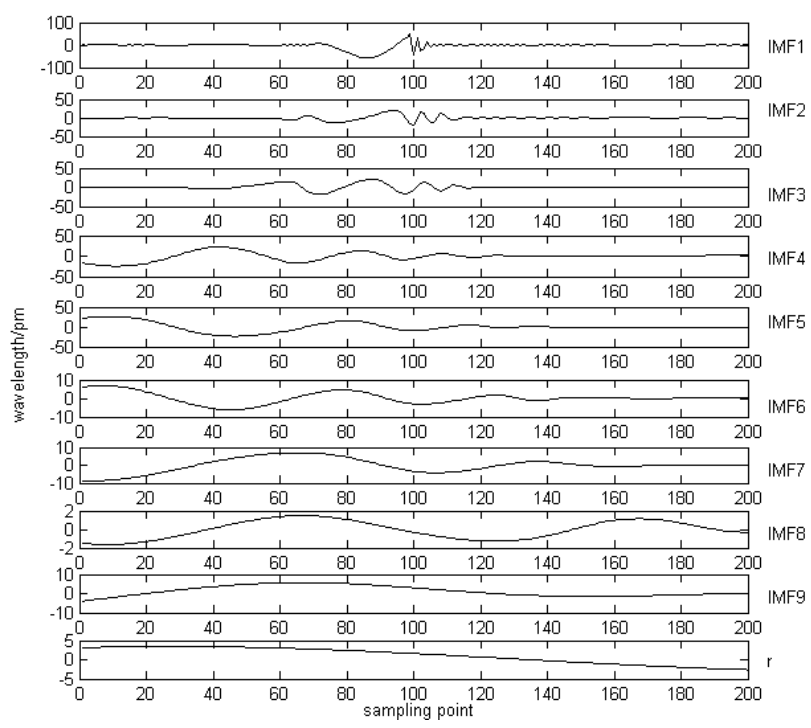

(d) The component graph of the impact signals at point $\mathrm{d}$.

Figure 7. The whitening EMD algorithm component graph of the impact signals at point a, b, c, d.

Table 4. Correlation table for each order IMF of the whitening EMD algorithm.

\begin{tabular}{llllllllll}
\hline IMF1 & IMF2 & IMF3 & IMF4 & IMF5 & IMF6 & IMF7 & IMF8 & IMF9 & $\boldsymbol{r}$ \\
\hline 0.4013 & 0.2785 & 0.2130 & 0.0916 & 0.0852 & 0.0747 & 0 & 0 & 0 & 0.0365 \\
0.3822 & 0.2857 & 0.2219 & 0.0963 & 0.0817 & 0.0709 & 0 & 0 & 0 & 0.0348 \\
0.3276 & 0.2449 & 0.1901 & 0.0911 & 0.0786 & 0.0693 & 0.0447 & 0 & 0 & 0.0298 \\
0.2548 & 0.1905 & 0.1479 & 0.0709 & 0.0611 & 0.0539 & 0.0384 & 0.0317 & 0.0287 & 0.0232 \\
\hline
\end{tabular}

Spectral analysis of the first three components of the whitening EMD algorithm is shown in Figure 8. The spectrogram shows that: (1) The trend of the change of the sensor spectrum and the distance between the sensor position and the impact point is basically the same, and the thickness of the laminate at the position where the sensor is located has the same tendency as the change of the sensor spectrum; (2) The frequency range of the band is gradually reduced from the high frequency component to the low frequency component, and the low frequency amplitude of the high frequency component is lower than the corresponding amplitude of the low frequency component; (3) The peak number of high frequency part of the spectrum increases with the decrease of the thickness of the 
laminate at the position where the sensor is located, which is related to the characteristics of variable thickness composite laminates. For example, the layer thickness of the laminate at the impact points a, b, c, d were $45.25 \mathrm{~mm}, 46.25 \mathrm{~mm}, 45.75 \mathrm{~mm}, 45.25 \mathrm{~mm}$, then the peak number of high frequency component of impact signals were 4, 2, 3, 4 (Due to the fact that the aliasing condition of the $S_{1}(t)$-component, i.e., IMF1, still exists, the number of peaks is obtained from the $S_{2}(t)$-component, i.e., IMF2, and the threshold for defining the peak value is $f_{k} / a$ ). Therefore, by using the improved whitening EMD algorithm, the impact energy feature extraction of variable thickness composite laminate can be better; and need to select a component $S_{3}(t)$ with larger spectral correlation and less aliasing to extract the spectral feature peak $f_{k}$.
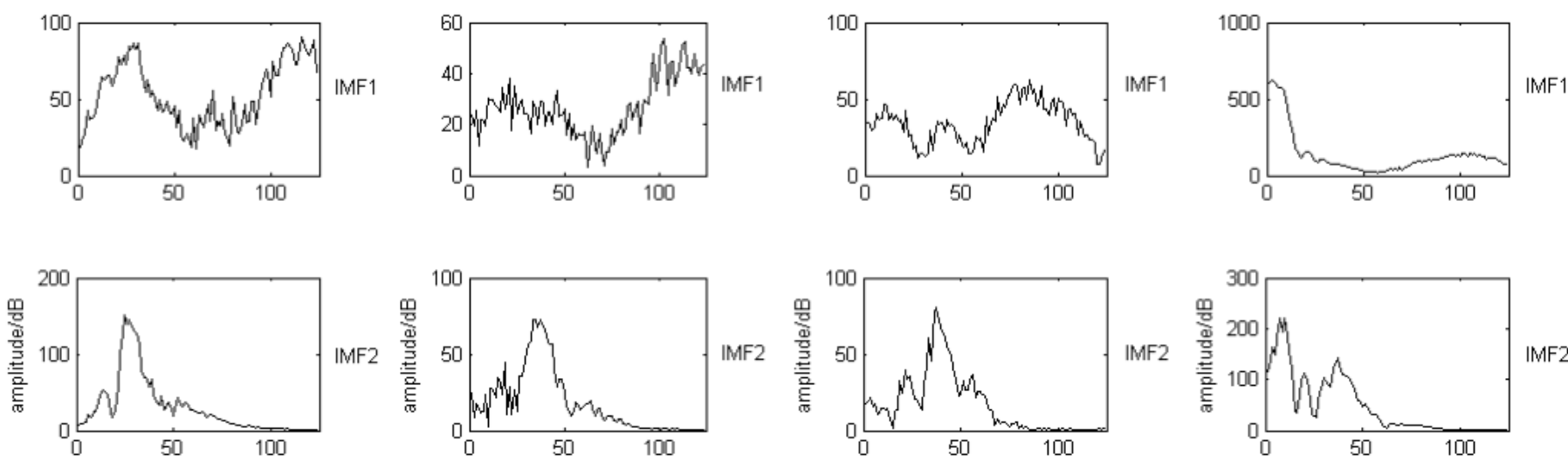

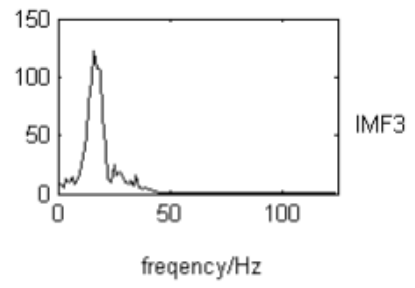

(a) Spectrogram at point a.

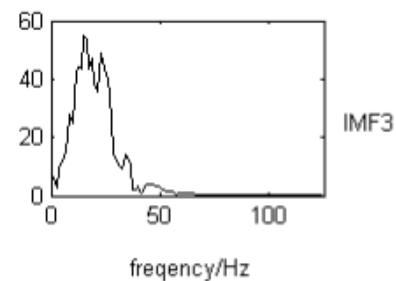

(b) Spectrogram at point $b$.

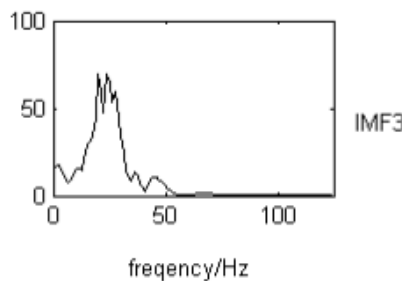

(c) Spectrogram at point $\mathrm{c}$.

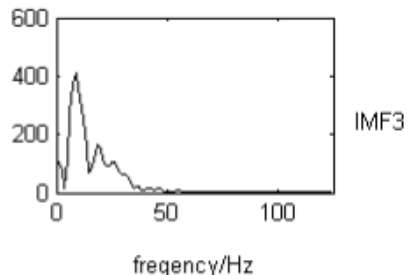

(d) Spectrogram at point $d$.

Figure 8. Spectrum of the first 3 components of signals at the impact point a, b, c, d using whitening EMD algorithm.

Take the sensor network signals at the impact point $(60 \mathrm{~mm}, 160 \mathrm{~mm})$ with three impact energies ( $1 \mathrm{~J}, 2 \mathrm{~J}, 3 \mathrm{~J}$ ) in Figure 5 as an example, the signal is whitening EMD decomposed, and obtain the sets of integrated thickness coefficient $J_{a 1}, J_{a 2}, J_{a 3}$ from the peak number sets $B_{a 1}, B_{a 2}, B_{a 3}$ when the impact energy is $1 \mathrm{~J}, 2 \mathrm{~J}$ and $3 \mathrm{~J}$, respectively. The spectrum analysis result of the third-order component (low-frequency signal below $50 \mathrm{~Hz}$ ) is shown in Figure 9. Figure 9 shows the spectral peak sets $F_{a 1}, F_{a 2}, F_{a 3}$ when the impact energy is $1 \mathrm{~J}$, $2 \mathrm{~J}$ and $3 \mathrm{~J}$, respectively. The spectral peak sets $F_{a 1}^{\prime}, F_{a 2}^{\prime}, F_{a 3}^{\prime}$ of the variable thickness plate was corrected by using $J_{a 1}, J_{a 2}$ and $J_{a 3}$, respectively, and the maximum value $F_{a 1 \max }^{\prime}, F_{a 2 \max }^{\prime}$ and $F_{a 3 \max }^{\prime}$ of the sets was calculated as $74.74,313.15$ and 417.28 , respectively.

In the same way, an impact energy feature set of the variable thickness composite laminate at 1-3 J can be obtained from all acquired impact signals and recognition steps (1)-(4), as shown in Table 5. In addition, the general impact energy feature set that is not corrected by the thickness coefficient is shown in Table 6 . 


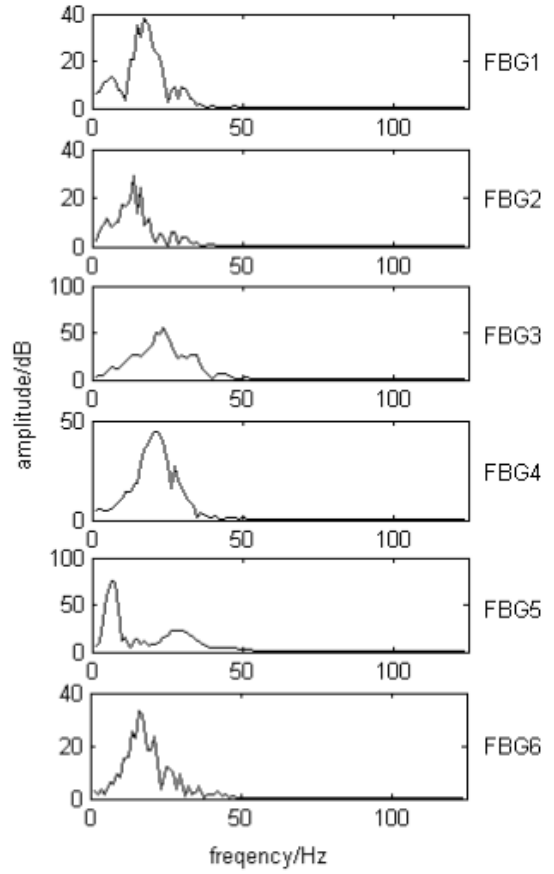

(a) $(60 \mathrm{~mm}, 160 \mathrm{~mm})$ with $1 \mathrm{~J}$ energy.

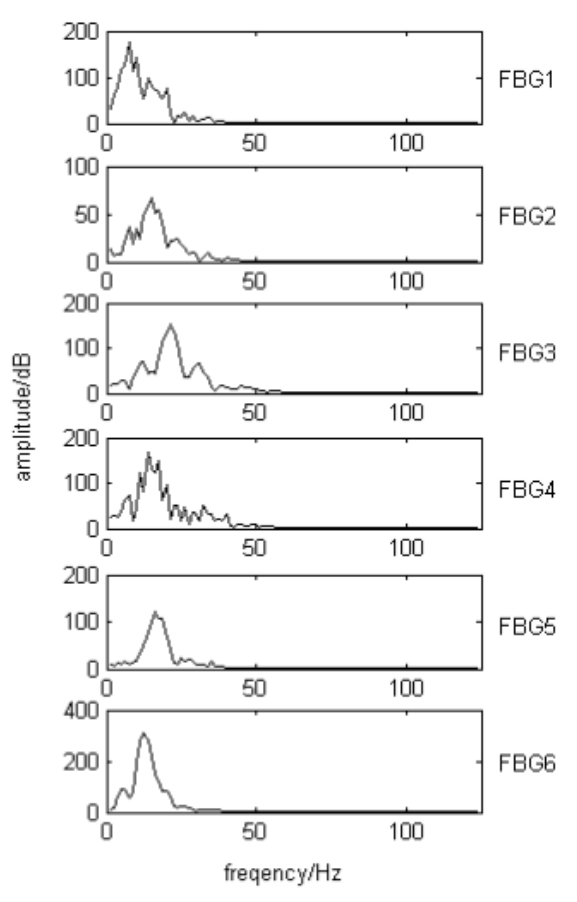

(b) $(60 \mathrm{~mm}, 160 \mathrm{~mm})$ with $2 \mathrm{~J}$ energy.

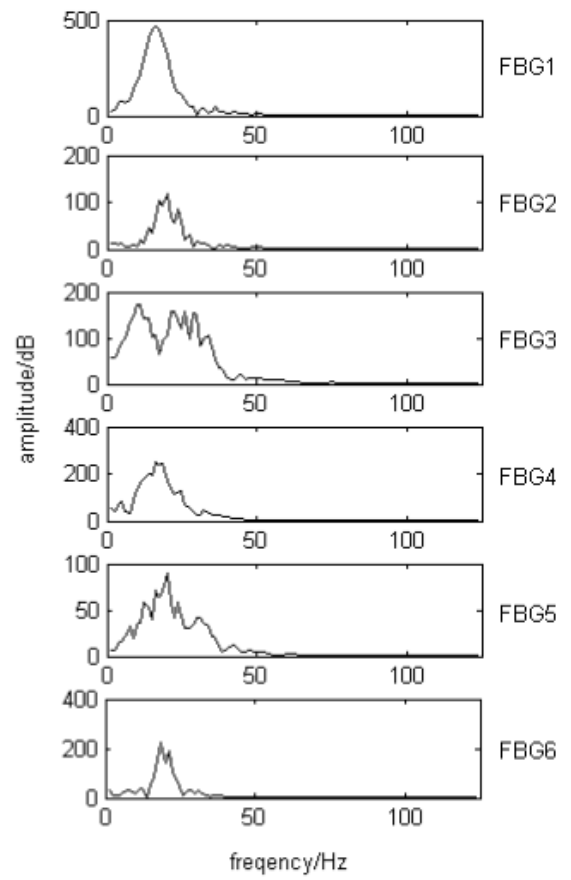

(c) $(60 \mathrm{~mm}, 160 \mathrm{~mm})$ with $3 \mathrm{~J}$ energy.

Figure 9. Spectrum of the third-order component of the signals at the impact point a $(60 \mathrm{~mm}, 160 \mathrm{~mm})$ using whitening EMD algorithm.

Table 5. Impact energy eigenvalues of the variable thickness composite laminate at 1-3 J.

\begin{tabular}{|c|c|c|c|c|c|c|c|c|c|c|c|c|}
\hline $\begin{array}{l}\text { Impact Point } \\
\text { Energy }\end{array}$ & 1 & 2 & 3 & 4 & 5 & 6 & 7 & 8 & 9 & 10 & 11 & 12 \\
\hline $1 \mathrm{~J}$ & 55.83 & 58.73 & 65.63 & 69.42 & 73.53 & 82.14 & 59.60 & 62.60 & 66.23 & 71.92 & 80.27 & 84.80 \\
\hline $2 \mathrm{~J}$ & 308.46 & 318.32 & 340.25 & 307.22 & 290.74 & 320.46 & 319.91 & 327.84 & 324.32 & 325.84 & 315.29 & 319.77 \\
\hline $3 \mathrm{~J}$ & 411.09 & 424.20 & 453.98 & 409.38 & 387.45 & 427.02 & 426.35 & 436.89 & 432.23 & 434.19 & 420.16 & 426.10 \\
\hline $\begin{array}{l}\text { Impact Point } \\
\text { Energy }\end{array}$ & 13 & 14 & 15 & 16 & 17 & 18 & 19 & 20 & 21 & 22 & 23 & 24 \\
\hline $1 \mathrm{~J}$ & 67.81 & 68.84 & 70.8 & 71.6 & 81 & 87 & 72. & 74.74 & 79.30 & 77.16 & 75.58 & 82.17 \\
\hline $2 \mathrm{~J}$ & 323.22 & 313.63 & 333.91 & 317.01 & 318.60 & 322.39 & 321.43 & 313.15 & 313.56 & 317.91 & 316.67 & 318.46 \\
\hline $3 \mathrm{~J}$ & 430.70 & 418.02 & 444.97 & 422.43 & 424.57 & 429.60 & 428.37 & 417.28 & 417.83 & 423.35 & 422.12 & 424.33 \\
\hline
\end{tabular}

Table 6. Impact energy eigenvalues at $1-3 \mathrm{~J}$.

\begin{tabular}{|c|c|c|c|c|c|c|c|c|c|c|c|c|}
\hline Impact Point & 1 & 2 & 3 & 4 & 5 & 6 & 7 & 8 & 9 & 10 & 11 & 12 \\
\hline $1 \mathrm{~J}$ & 49.25 & 52.15 & 59.05 & 69.24 & 78.80 & 88.72 & 53.02 & 56.02 & 61.23 & 71.18 & 85.54 & 91.38 \\
\hline $2 \mathrm{~J}$ & 272.12 & 282.25 & 306.39 & 307.66 & 310.74 & 345.08 & 284.60 & 293.77 & 300.11 & 321.70 & 335.98 & 345.35 \\
\hline $3 \mathrm{~J}$ & 362.63 & 376.66 & 407.97 & 409.83 & 415.20 & 461.33 & 379.24 & 390.94 & 399.58 & 429.72 & 447.73 & 459.18 \\
\hline $\begin{array}{l}\text { Impact Point } \\
\text { Energy }\end{array}$ & 13 & 14 & 15 & 16 & 17 & 18 & 19 & 20 & 21 & 22 & 23 & 24 \\
\hline $1 \mathrm{~J}$ & 63.86 & 66.21 & 69.52 & 71.10 & 85.59 & 94.51 & 74.98 & 80.53 & 83.78 & 83.74 & 80.58 & 88.75 \\
\hline $2 \mathrm{~J}$ & 303.98 & 301.98 & 327.70 & 314.53 & 336.19 & 346.04 & 333.77 & 337.42 & 331.70 & 343.98 & 338.05 & 344.87 \\
\hline $3 \mathrm{~J}$ & 405.58 & 402.03 & 436.70 & 419.37 & 448.03 & 461.76 & 444.79 & 449.63 & 441.42 & 458.82 & 449.93 & 458.33 \\
\hline
\end{tabular}

\subsection{Analysis of Low Velocity Impact Energy Recognition}

Combining with the impact energy feature sets of three impact energy, the impact energy eigenvalue ranges of the variable thickness composite laminate at 1, 2, $3 \mathrm{~J}$ are $(55.83,87.93),(290.74,340.25)$ and $(387.45,453.98)$ respectively, while the impact energy 
eigenvalue ranges are $(49.25,94.51),(272.12,346.04),(362.63,461.76)$ respectively. In order to test the energy recognition performance of this method, 20 impact points were selected on the variable thickness composite specimens to verify the effect of thickness coefficient correction on energy recognition performance. Among them, the impact points L1-12 is in a large thickness area and the rest is in a small thickness area. The recognition error is the absolute error between the actual impact energy and the predicted impact energy.

Figure 10 and Table 7 show the comparison of impact energy at 20 impact points. The results show that the recognition results with the thickness coefficient correction (the second recognized impact energy) has better performance than the uncorrected result (the first recognized impact energy). When uncorrected, the energy error at verification point L2 $(20 \mathrm{~mm}, 50 \mathrm{~mm})$ and point L19 $(210 \mathrm{~mm}, 180 \mathrm{~mm})$ is larger than $0.6 \mathrm{~J}$. As shown in Tables 5 and 6, the uncorrected feature set is more scattered due to the changes in the thickness of the laminate at the position where the corresponding impact point are located, so uncorrected results will lead to greater energy errors.

Table 7. Recognition results of the 20 verification points.

\begin{tabular}{|c|c|c|c|c|c|c|c|}
\hline Impact Point & $\begin{array}{l}\text { The Actual } \\
\text { Impact } \\
\text { Energy (J) }\end{array}$ & $\begin{array}{l}\text { The First } \\
\text { Recognized } \\
\text { Impact } \\
\text { Energy } \\
\text { (J)/Error }\end{array}$ & $\begin{array}{l}\text { The Second } \\
\text { Recognized } \\
\text { Impact } \\
\text { Energy } \\
\text { (J)/Error }\end{array}$ & Impact Point & $\begin{array}{l}\text { The Actual } \\
\text { Impact } \\
\text { Energy (J) }\end{array}$ & $\begin{array}{l}\text { The First } \\
\text { Recognized } \\
\text { Impact } \\
\text { Energy } \\
\text { (J)/Error }\end{array}$ & $\begin{array}{l}\text { The Second } \\
\text { Recognized } \\
\text { Impact } \\
\text { Energy } \\
\text { (J)/Error }\end{array}$ \\
\hline L1 & 1 & $0.78 / 22 \%$ & $0.86 / 14 \%$ & L11 & 1 & $0.96 / 4 \%$ & $0.97 / 1.5 \%$ \\
\hline L2 & 3 & $2.35 / 21.67 \%$ & $2.62 / 12.67 \%$ & L12 & 3 & $3.44 / 14.67 \%$ & $3.05 / 1.67 \%$ \\
\hline L3 & 1 & $0.82 / 18 \%$ & $0.91 / 9 \%$ & L13 & 2 & $1.98 / 1 \%$ & $2 / 0 \%$ \\
\hline L4 & 2 & $1.67 / 16.5 \%$ & $1.83 / 8.5 \%$ & L14 & 1 & $0.83 / 17 \%$ & $0.92 / 8 \%$ \\
\hline L5 & 1 & $0.87 / 13 \%$ & $0.95 / 5 \%$ & L15 & 1 & $1.16 / 16 \%$ & $1.05 / 5 \%$ \\
\hline L6 & 2 & $1.78 / 11 \%$ & $1.93 / 3.5 \%$ & L16 & 2 & $2.13 / 6.5 \%$ & $2.06 / 3 \%$ \\
\hline L7 & 3 & $2.66 / 11.33 \%$ & $2.87 / 4.33 \%$ & L17 & 3 & $3.14 / 4.67 \%$ & $3.02 / 0.67 \%$ \\
\hline L8 & 2 & $2.21 / 10.5 \%$ & $2.07 / 3.5 \%$ & L18 & 1 & $0.95 / 5 \%$ & $1 / 0 \%$ \\
\hline L9 & 1 & $1.08 / 8 \%$ & $1.03 / 3 \%$ & L19 & 3 & $3.62 / 20.67 \%$ & $3.35 / 11.67 \%$ \\
\hline L10 & 3 & $3.25 / 8.33 \%$ & $3.04 / 1.33 \%$ & L20 & 2 & $2.02 / 1 \%$ & $2 / 0 \%$ \\
\hline
\end{tabular}

Influenced by factors such as aliasing of impact signal on the composite structure with variable thickness, the eigenvalues of low velocity impact energy of most verification points in the recognition result are between two energy feature sets, only L13 (190 mm, $20 \mathrm{~mm})$ and L18 (190 mm, $170 \mathrm{~mm})$ and L20 $(150 \mathrm{~mm}, 190 \mathrm{~mm})$ are within the energy feature set range of the corresponding level after the thickness coefficient correction. Meanwhile, when uncorrected, the impact point on a large thickness area shows a large recognition error with respect to a small thickness area. The average errors of large thickness area and small thickness area are respectively $13.25 \%$ and $8.98 \%$. The larger error of the point in large thickness areas is caused by a reduction in the spectrum amplitude of the impact signal, depending on the impact location and layer thickness, with greater error without uncorrected recognition. Therefore, after the impact signal is whitening EMD decomposed to achieve the basic effect for the impact energy feature extraction, the impact energy recognition performance through thickness coefficient correction can be improved, the thickness coefficient changes according to the impact position and thickness.

From the comparison results, the thickness coefficient correction method can more accurately evaluate the actual energy of low velocity impact. In particular, the average error of large thickness areas with low sensitivity decreased significantly from $13.25 \%$ to $5.67 \%$. The proposed energy recognition method successfully identified 1-3 J impact energy for all verification points, with the maximum error of $14 \%$ and the average error of $4.82 \%$. In addition, as the thickness difference of the test specimen is only $5.5 \%$, after verifying the effectiveness of the thickness coefficient correction method, it is necessary to analyze whether the correction effect will be greatly enhanced with the increase of the thickness difference. 


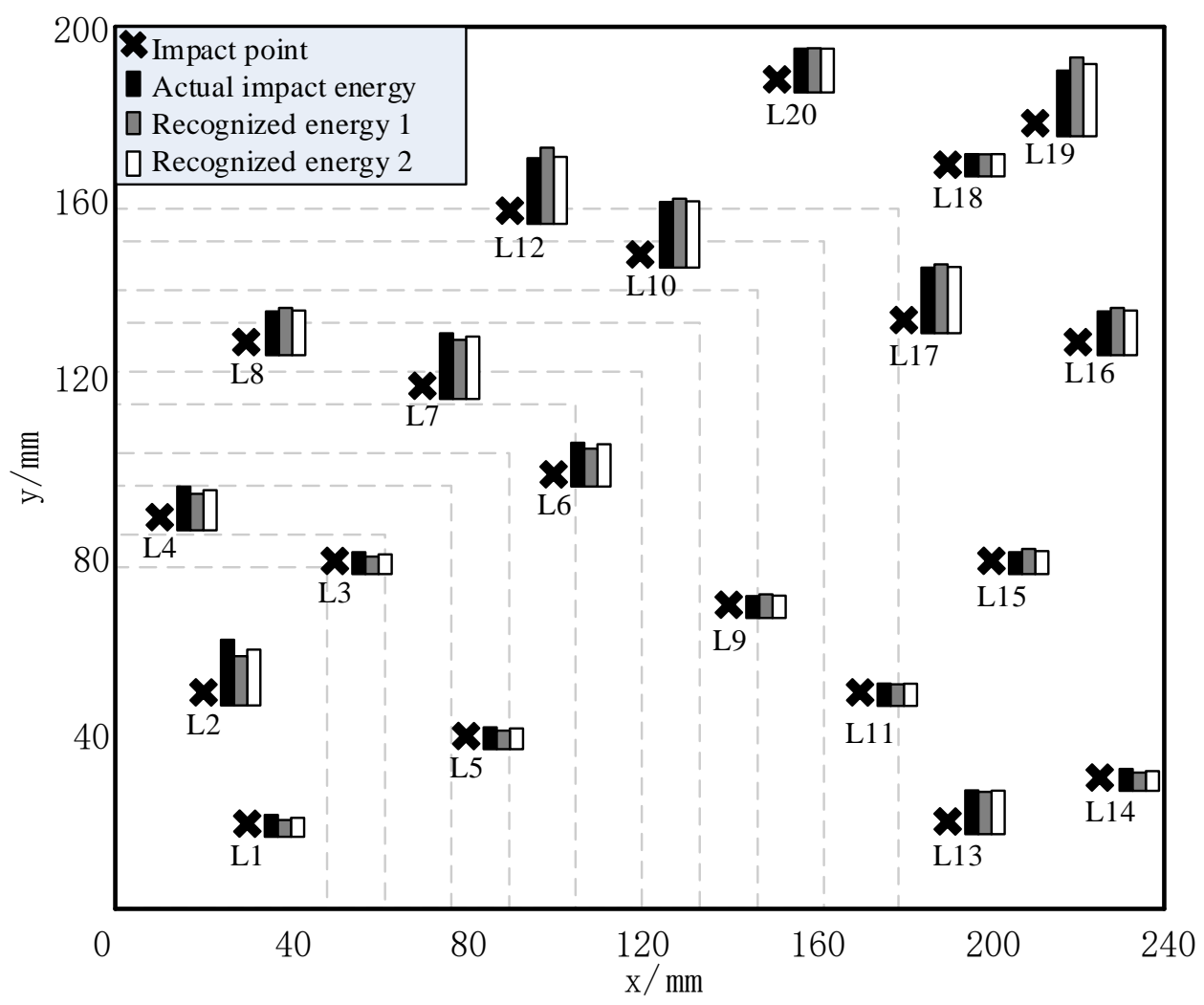

Figure 10. The schematic of the low velocity impact energy verification experimental results on variable thickness composite laminate.

By analyzing the experimental results, the following problems can be further discussed.

(1) The relationship between the thickness of the plate and the number of sensors required. For the composite plate with general uniform thickness, a slight increase in the thickness of the plate does not need to add more sensors, but for the variable thickness plate, because the impact signal aliasing in its interior is more serious, which can be seen from the same sensor network, the recognition error of the large thickness area is greater than that of the small thickness area.

(2) The relationship between sensor location and impact energy monitoring and identification results. For this variable thickness specimen, two 3-sensor combinations in sensor network were selected as examples to compare impact energy monitoring and identification results. As shown in Table 8, the average identification error of sensor combination in small thickness area is 7.73, which is better than that in large thickness area by 9.12. This is because the greater the thickness, the higher the degree of signal aliasing and attenuation. This shows that the position of the sensor will affect the monitoring and recognition results.

(3) How to find the best sensor position related to the impact point. For the monitoring of multiple impact points, the mechanical analysis and structural characteristics can be used for preliminary search. Next, the point selection algorithm should be introduced to simulate the identification results of various sensor combinations to determine the optimal layout scheme.

(4) Whether it can further reduce the number of sensors in the sensor network. Using three sensors in the sensor network to identify the impact energy, the average error is more than $5 \%$, it can be seen that in the current recognition method, if the number of sensors need to be reduced, the accuracy will be greatly affected. Next, the recognition method will be improved to solve this problem.

(5) At present, there is little research on the impact energy monitoring of complex composite laminates. Compared with the existing related research, it is found that the accuracy of the identification results in this paper is between the identification results of 
uniform thickness composite laminates and more complex composite structures (stiffened plates, etc.), and the identification results of optical fiber sensor networks are affected by the sampling frequency of the demodulator.

In general, for the aviation low velocity impact energy monitoring, the identification results obtained in this paper meet the requirements of engineering application.

Table 8. Recognition results comparison of sensor combinations.

\begin{tabular}{llll}
\hline Impact Point & $\begin{array}{l}\text { Recognition Error } \\
\text { of Sensor } \\
\text { Combination }\end{array}$ & Impact Point & $\begin{array}{l}\text { Recognition Error } \\
\text { of Sensor } \\
\text { Combination } \mathbf{( 4 , 5 , 6 )}\end{array}$ \\
\hline L1 & $14.33 \%$ & L1 & $20 \%$ \\
L2 & $15 \%$ & L2 & $18.33 \%$ \\
L3 & $12 \%$ & L3 & $13 \%$ \\
L4 & $13 \%$ & L4 & $12.67 \%$ \\
L5 & $5.5 \%$ & L5 & $5.33 \%$ \\
L6 & $5.5 \%$ & L6 & $6.5 \%$ \\
L7 & $9.5 \%$ & L7 & $6.67 \%$ \\
L8 & $9.33 \%$ & L8 & $6.33 \%$ \\
L9 & $4.67 \%$ & L1 & $6.33 \%$ \\
L10 & $7.5 \%$ & L11 & $2 \%$ \\
L11 & $2.33 \%$ & L12 & $6 \%$ \\
L12 & L13 & $2.5 \%$ \\
L13 & $9.33 \%$ & L14 & $5 \%$ \\
L14 & $0.5 \%$ & L15 & $13.33 \%$ \\
L15 & $11.5 \%$ & L16 & $8.67 \%$ \\
L16 & $9 \%$ & L17 & $5 \%$ \\
L17 & $10 \%$ & L18 & $1.67 \%$ \\
L18 & $6 \%$ & L19 & $0.33 \%$ \\
L19 & $8.33 \%$ & L20 & $13.5 \%$ \\
L20 & $20.5 \%$ & $1.5 \%$ \\
\hline
\end{tabular}

\section{Conclusions}

To monitor the low velocity impact load of the composite laminates, and to provide a basis for judging the degree of impact damage, aiming at the impact signal characteristics of the composite structure with variable thickness, using fiber grating sensing and monitoring technique, a low velocity impact energy recognition method based on whitening EMD algorithm is proposed by adapting thickness coefficient correction method, and the steps of low velocity impact energy recognition for the composite structure with variable thickness are given. The FBG impact energy monitoring system is built by using the fiber grating sensing technology. The impact energy feature extraction based on whitening EMD algorithm is carried out according to the characteristics of variable thickness composites structure. The impact energy feature sets of the impact signals on the variable thickness specimen at $1 \mathrm{~J}, 2 \mathrm{~J}, 3 \mathrm{~J}$ energy were established, and the energy recognition verification experiment was conducted.The results show:

(1) An improved whitening EMD method was proposed which can effectively avoid modal aliasing of high-frequency intrinsic mode signals for variable thickness composites, improve the validity of impact eigenvalues, increase the accuracy of energy recognition, and better extract the impact energy feature of variable thickness composite laminate.

(2) A low velocity impact energy recognition system for variable thickness composite structure was designed and built. The system ensures the effectiveness of the impact energy recognition method and has the advantages of reliability, stability, anti-interference, and distribution.

(3) The performance of the proposed impact energy recognition method was verified by experiments. Experiments show that this method can accurately estimate the 1-3 J impact energy, of which the average error is $4.82 \%$. The recognition result accords with the scope 
of engineering application. The thickness coefficient correction step (especially in large thickness areas) significantly improves the recognition performance.

(4) Since the thickness difference of the specimen is not significant, after validating the effectiveness of the thickness coefficient correction method, the future work needs to focus on the relationship between the performance of the correction method and the thickness difference of the structure.

(5) Next, point selection algorithm should be introduced to simulate the recognition results of various sensor combinations to determine the optimal layout. In addition, further improvement is needed for the recognition method to solve the problem of sensor reduction.

Author Contributions: Conceptualization, G.L. and Y.X.; methodology, Y.X.; software, T.Z.; validation, G.L. and T.Z.; formal analysis, G.L.; investigation, T.Z.; resources, G.L. and T.Z.; data curation, G.L. and T.Z.; writing — original draft preparation, G.L.; writing—review and editing, Y.X. and T.Z.; visualization, G.L. and T.Z.; supervision, Y.X. All authors have read and agreed to the published version of the manuscript.

Funding: This research was funded by the National Natural Science Foundation of China (Grant No.61973178), Industry-University-Research Cooperation Project in Jiangsu province (BY2020177, BY2020178).

Data Availability Statement: The data presented in this study are available on request from the corresponding author.

Conflicts of Interest: The authors declare no conflict of interest.

\section{References}

1. Khaled, S.; Ahmed, S.; Faleh, A. Damage Characterization Using Thermography of Composite Plates Subjected to Low Velocity Impact Loads. J. Mater. Sci. Eng. 2019, 8, 1-16.

2. Peter, O.; Sjǒblom, P. On Low-Velocity Impact Testing of Composite Materials. J. Compos. Mater. 1988, 22, 30-52.

3. Liu, D.; Malvern, L. Matrix Cracking in Impacted Glass/Epoxy Plates. J. Compos. Mater. 1987, 21, 594-609.

4. Denis, D.; Petersen, E.; Stefaniak, D. Damage resistance and low-velocity impact behaviour of hybrid composite laminates with multiple thin steel and elastomer layers. Compos. Struct. 2020, 238, 111851.

5. Colombo, L.; Oboe, D.; Sbarufatti, C. Shape sensing and damage identification with iFEM on a composite structure subjected to impact damage and non-trivial boundary conditions. Mech. Syst. Signal Process. 2021, 148, 107163.

6. Shirsendu, S.; Pawel, K.; Maciej, R. Online detection of barely visible low-speed impact damage in 3D-core sandwich composite structure. Compos. Struct. 2018, 185, 646-655.

7. Zhu, Q.; Xu, C.; Yang, G. Experimental research on damage detecting in composite materials with FBG sensors under low frequency cycling. Int. J. Fatigue 2017, 101, 61-66.

8. Bacciocchi, M.; Eisenberger, M.; Fantuzzi, N. Vibration analysis of variable thickness plates and shells by the Generalized Differential Quadrature method. Compos. Struct. 2016, 156, 218-237.

9. Tornabene, F.; Fantuzzi, N.; Bacciocchi, M. The local GDQ method applied to general higher-order theories of doubly-curved laminated composite shells and panels: The free vibration analysis. Compos. Struct. 2014, 116, 637-660.

10. Sachse, R.; Pickett, A.; Middendorf, P. Simulation of impact and residual strength of thick laminate composites. Compos. Part B 2020, 195, 108070.

11. Divse, V.; Marla, D.; Joshi, S. Finite element analysis of tensile notched strength of composite laminates. Compos. Struct. 2021, $255,112880$.

12. Zhao, Y.; Hu, D.; Zhang, M. The Location Monitoring of Fatigue Crack Damage by Using the Spectral Area Extracted from FBG Spectra. Sensors 2020, 20, 2375.

13. Zhang, C.; Alam, Z.; Sun, L. Fibre Bragg grating sensor-based damage response monitoring of an asymmetric reinforced concrete shear wall structure subjected to progressive seismic loads. Struct. Control Health Monitor. 2019, 26.

14. Park, S.; Jang, B.; Lee, Y. Detection of impact location for composite stiffened panel using FBG sensors. Adv. Mater. Res. 2010, 978, 895-898.

15. Hiche, C.; Coelho, C.; Chattopadhyay, A. A strain amplitude-based algorithm for impact location on composite laminates. J. Int. Mater. Syst. Struct. 2011, 22, 2061-2067.

16. Park, C.; Kim, J.; Jun, S. Localizations and force reconstruction of low-velocity impact in a composite panel using optical fiber sensors. Adv. Compos. Mater. 2012, 21, 357-369.

17. Jang, B.; Lee, Y.; Kim, C. Impact source localization for composite structures under external dynamic loading condition. Adv. Compos. Mater. 2015, 24, 359-374.

18. Sai, Y.; Zhao, X.; Wang, L. Impact Localization of CFRP Structure Based on FBG Sensor Network. Photonic Sens. 2020, 10, 88-96. 
19. Zhang, W.; Zhang, M.; Lan, Y. Detection of Crack Locations in Aluminum Alloy Structures Using FBG Sensors. Sensors 2020, $20,347$.

20. Yu, J.; Liang, D. Impact localization system of composite structure based on recurrence quantification analysis by using FBG sensors. Opt. Fiber Technol. 2019, 49, 7-15.

21. Qi, K.; Ke, Q.; Liao, Q. An Improved EMD Parallel Steganography Algorithm. J. Phys. 2020, 1621, 012006.

22. Yue, S.; Wang, Y.; Wei, L. The joint empirical mode decomposition-local mean decomposition method and its application to time series of compressor stall process. Aerosp. Sci. Technol. 2020, 105, 105969. [CrossRef]

23. Zhang, Y.; Fu, H.; Wang, Z. Open hole fatigue characteristic and probabilistic model for fatigue life prediction of CCF300/QY8911 and T300/QY8911 composite laminates. J. Compos. Mater. 2015, 49, 3205-3214. 